05

\title{
Термический гистерезис при плавлении и кристаллизации макрообъектов
}

\author{
() В.Д. Александров, Е.А. Покинтелица, А.Ю. Соболев
}

Донбасская национальная академия строительства и архитектуры, 286123 Макеевка, Донбасс, Россия

e-mail: Ink0013@gmail.com

(Поступило в Редакцию 4 июля 2016 г.)

На основании термограмм нагревания и охлаждения, с учетом фазовых превращений типа плавлениекристаллизация, проанализированы различные термические гистерезисные процессы для макрообъектов. Выявлено два вида термического гистерезиса при равновесной и неравновесной кристаллизации. Показаны пути изменения энергии Гиббса в обоих случаях.

DOI: $10.21883 / J T F .2017 .05 .44445 .1965$

В последнее время большое внимание уделяется температурным гистерезисам (ТГ) при плавлении и кристаллизации малых частиц [1-4]. В основном их связывают с размерными зависимостями различных физических характеристик (температуры и энтальпии плавления, теплоемкости, поверхностного натяжения и др.). Перенесем наше внимание к макрообъектам и проанализируем наличие ТГ у них. Если гистерезисные эффекты имеют место, то возникает вопрос о том, чем они могут быть обусловлены, поскольку о влиянии размерных факторов в данном случае говорить не приходится.

Анализ многочисленных работ по изучению процессов плавления и кристаллизации сплошь и рядом указывает на возможность наличия, либо на отсутствие ТГ [5-10]. Термограммы плавления и кристаллизации обычно записываются в одном направлении. Петля термического гистерезиса формируется при совмещении кривых нагревания и охлаждения с учетом прямого и обратного фазовых переходов. Начертим схематические термограммы при обычной записи в координатах температура $T$ - время $\tau$ при нагреве и охлаждении. Для построения и анализа петель гистерезиса развернем кривые охлаждения на $180^{\circ}$ относительно оси симметрии и совместим их с кривыми нагревания. Стрелки $(\rightarrow)$ и $(\leftarrow)$ обозначают направления записей. Примем, что за один цикл $(C)$ происходят процессы нагревания и охлаждения, за полцикла от нуля до $\frac{1}{2} C$ идет нагревание, а от $\frac{1}{2} C$ до $C-$ охлаждение.

Начнем с „простого“ цикла (рис. 1,a), характеризующего нагрев по пути $a \rightarrow b \rightarrow c \rightarrow d_{k}$ с плавлением $(b \rightarrow c)$ при $T_{L}$, и охлаждение по пути $d_{k} \rightarrow e \rightarrow f \rightarrow g$ с равновесной кристаллизацией $(e \rightarrow f)$ при температуpe $T_{s}$, равной температуре плавления $T_{L}$.

При зеркальном отражении пунктирная линия охлаждения совпадает с кривой нагревания. Видно, что нет петли гистерезиса и нет разницы между температурами плавления $T_{L}$ и кристаллизации $T_{S}$, а также между энтальпиями плавления $\Delta H_{L S}$ и кристаллизации $\Delta H_{S L}$, т. е. $T_{S}=T_{L}, \Delta H_{L S}=\Delta H_{S L}$.
На кривых нагревания и охлаждения, показанных на рис. 1, $a$, не обозначены эндо- и экзотермические явления поглощения и выделения теплоты, сопровождающие соответствующие фазовые переходы. Рассмотрим реальные формы кривых (рис. $1, b$ ), учитывающие эти процессы. Как видим, при правильной записи кривые нагревания и охлаждения не накладываются друг на друга, как на рис. 1, a. И если температура кристаллизации $T_{S}$ совпадает с температурой плавления $T_{L}$, то площади фигур $b c d b$ (эндоэффект) и sff' $b$ (экзоэффект) смещены друг относительно друга. Вопрос в том, характеризует ли подобное смещение тепловой гистерезис. Кстати, при записи эндо- и экзотермических эффектов плавления и кристаллизации методом дифференциального термического анализа (ДТА) соответствующие пики также смещаются друг относительно друга [5-7].

Проанализируем теперь термограммы нагревания и охлаждения в случае, когда равновесная кристаллизация происходит при температуре $T_{S}<T_{L}$. На рис. 2, $a$ показаны подобные кривые, на которых нет участков, характеризующих поглощение и выделение теплоты фазовых переходов. Сопоставляя кривые нагревания (сплошная линия) в период от нуля до $\frac{1}{2} C$ с кривой охлаждения (пунктирная линия) в период от $\frac{1}{2} C$ до $C$, видим отчет-

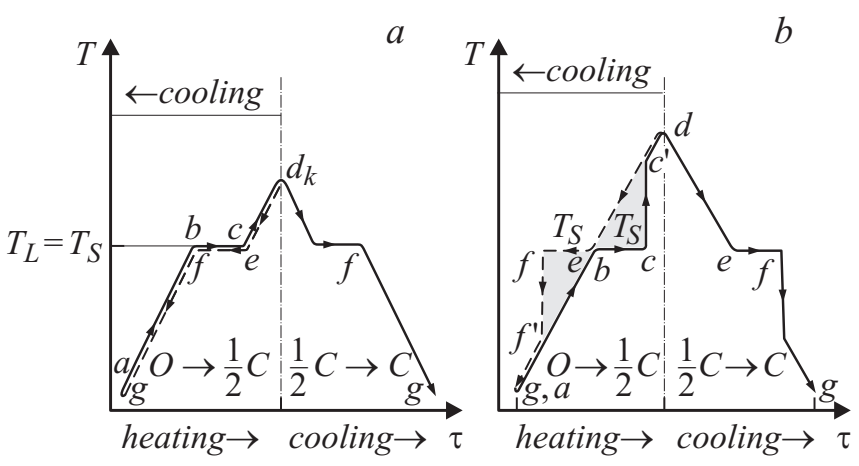

Рис. 1. Схематические термограммы, характеризующие отсутствие температурного гистерезиса без учета $(a)$ и с учетом $(b)$ энтальпий фазовых переходов. 
$a$

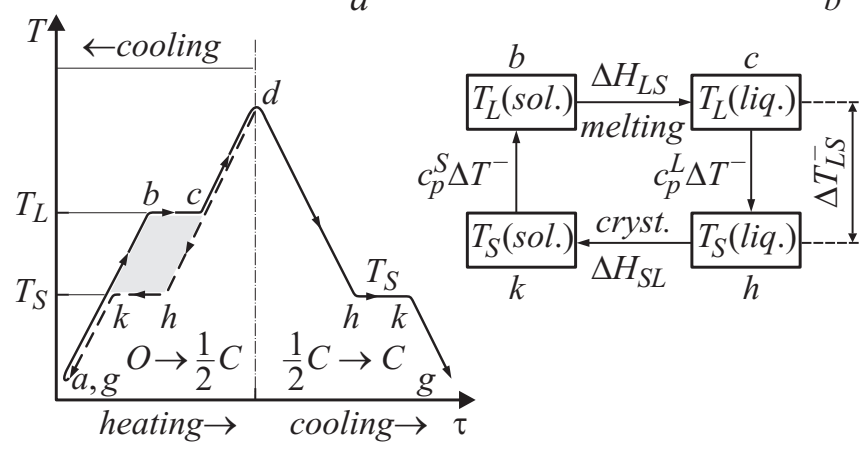

Рис. 2. Термограмма, характеризующая термический гистерезис первого рода $(a)$, и схема изменения энтальпий фазовых превращений $(b)$.

ливую фигуру петли гистерезиса $b c h k b$. Особо отметим тот факт, что как плавление, так и кристаллизация являются изотермическими. Таким образом, при наличии своеобразного переохлаждения $\Delta T_{L S}^{-}$имеет место равновесная кристаллизация при $T_{S}$.

Назовем явление, рассмотренное на рис. 2, термическим гистерезисом первого рода (ТГ-I). Схема изменения энтальпий плавления и кристаллизации при ТГ-I, исходя из рис. $2, a$, представлена на рис. $2, b$.

Из нее следует, что энтальпия плавления $\Delta H_{L S}$ отличается от энтальпии кристаллизации $\Delta H_{S L}$. Для установления связи между $\Delta H_{L S}$ и $\Delta H_{S L}$ обратимся к петле гистерезиса (рис. 2,a). Она состоит из двух изотерм $b c$, $h k$ и двух участков с нагревом $(k \rightarrow b)$ твердой фазы и охлаждением $(c \rightarrow h)$ жидкой фазы. Тогда для кругового процесса $k \rightarrow b \rightarrow c \rightarrow h \rightarrow k$ очевидно

$$
c_{p}^{S} \Delta T_{L S}^{-}+\Delta H_{L S}=c_{p}^{L} \Delta T_{S L}^{-}+\Delta H_{S L},
$$

откуда в первом приближении вычисляем энтальпию кристаллизации $\Delta H_{S L}$ по формуле

$$
\Delta H_{S L}=\Delta H_{L S}-\Delta c_{p} \Delta T_{L S}^{-}
$$

Гистерезис второго рода (ТГ-II) возникает при сопоставлении процессов плавления и неравновесной кристаллизации из переохлажденного состояния. Проанализируем термограммы нагревания $a \rightarrow b \rightarrow c \rightarrow d$ и охлаждения $d \rightarrow e_{k} \rightarrow e \rightarrow f \rightarrow g$, показанные на рис. 3, $a$.

В данном случае кристаллизация начинается при температуре $T_{\min }$ (точка $e_{k}$ ), затем за счет взрывной кристаллизации температура поднимается до температуры плавления $T_{L}$. В результате затвердевает лишь часть $\beta$ жидкой фазы. Далее идет изотермическая докристаллизация оставшейся части $(1-\beta)$ расплава за время $\tau_{3}$ по пути $e \rightarrow f$ при температуре $T_{S}=T_{L}$. При наложении кривых виден гистерезисный эффект в виде заштрихованного треугольника сее $e_{k} c$. Подобное явление характерно только для начальной стадии кристаллизации макрообъектов, т.е. для этапа зародышеобразования за инкубационный период $\tau_{1}$ и время $\tau_{2}$ коагуляции зародышей [8]. Если уменьшать массу вещества, то кристаллизация может завершиться либо в точке $e$ (по пути $d \rightarrow e_{k} \rightarrow e \rightarrow g^{\prime}$ ), либо в точке $e_{k}$ (по пути $d \rightarrow e_{k} \rightarrow g^{\prime \prime}$ ) и т.д. Для микро- и наночастиц температура начала кристаллизации может опускаться гораздо ниже $T_{\min }$, что приведет к возрастанию величины термического гистерезиса.

Схема изменения энтальпий при ТГ-II (рис. 3,b) в соответствии с термограммой рис. 3, $a$ показывает, что общая энтальпия кристаллизации состоит из трех составляющих (энтальпий $\Delta H_{1}$ зародышеобразования, $\Delta H_{2}$ коагуляции и $\Delta H_{3}$ докристаллизации): $\Delta H_{S L}=\Delta H_{1}+\Delta H_{2}+\Delta H_{3}$.

Еще более замысловатые гистерезисные фигуры вырисовываются при наложении друг на друга кривых нагревания и охлаждения, получаемых в реальных условиях при температуре докристаллизации $T_{S}$, равной температуре плавления $T_{L}$, а также комбинированного гистерезиса, сочетающего в себе термические гистерезисы первого и второго рода при $T_{S}<T_{L}$. При комбинированном гистерезисе $\Delta H_{L S} \neq \Delta H_{S L}, T_{S}<T_{L}, T_{L}$ - const, $T_{S}$ - const, $\Delta T_{L}^{-}=\Delta T_{L S}^{-}+\Delta T_{S}^{-}$, где $\Delta T_{L}^{-}$и $\Delta T_{S}^{-}-$ переохлаждения относительно температур $T_{L}$ и $T_{S}$, а $\Delta T_{L S}^{-}=T_{L}+T_{S}$.
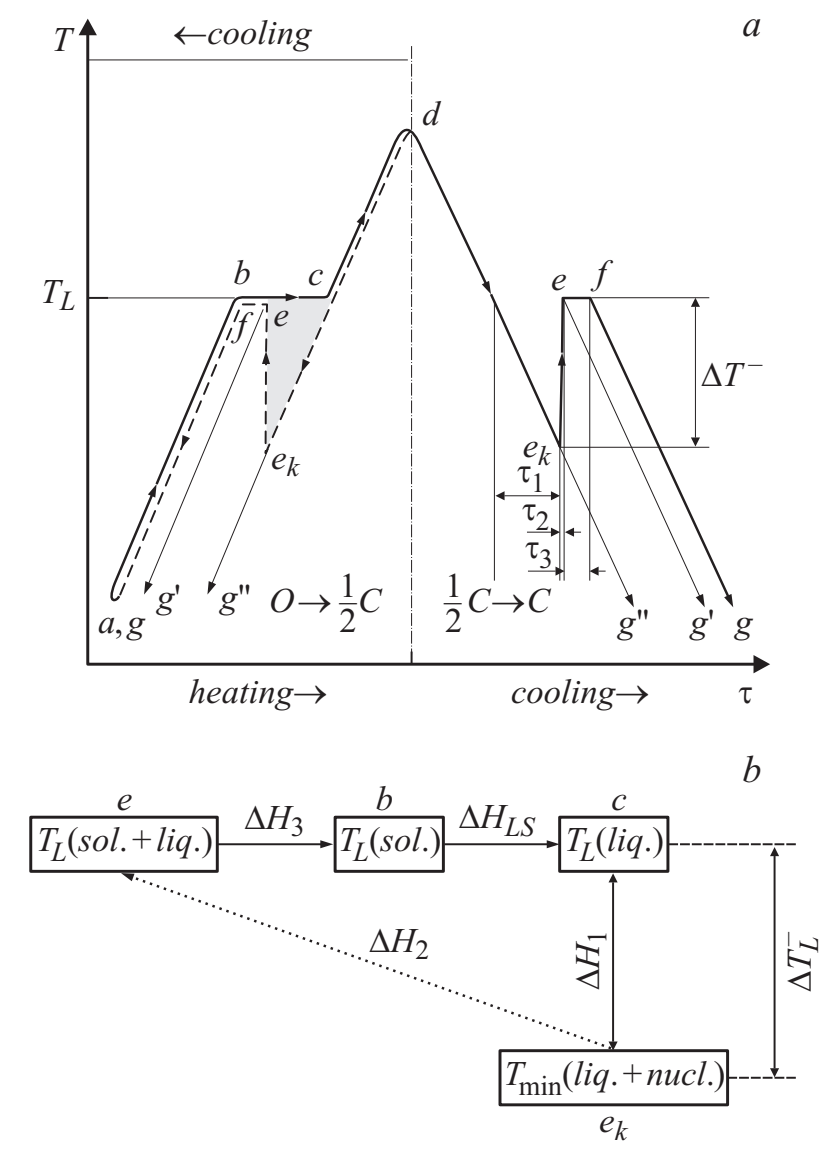

Рис. 3. Термограмма, характеризующая термический гистерезис второго рода $(a)$ и схема изменения энтальпий фазовых превращений $(b)$. 


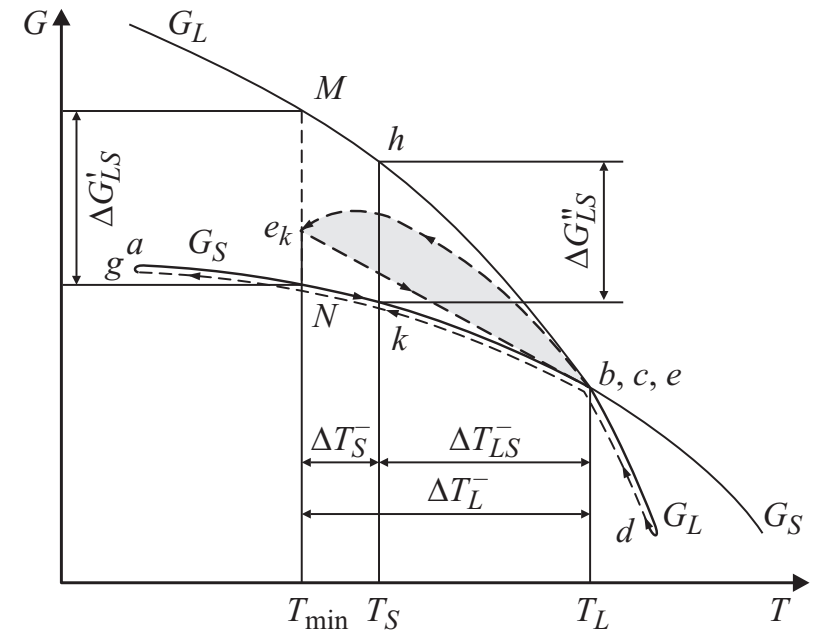

Рис. 4. Зависимость энергий Гиббса для жидкой $\left(G_{L}\right)$ и твердой $\left(G_{S}\right)$ фаз от температуры при ТГ-І и ТГ-ІІ.

Рассмотрим пути изменения энергий Гиббса для жидкой $G_{L}$ и твердой $G_{S}$ фаз (рис. 4) при повышении и понижении температуры.

Очевидно, что пути $(a \rightarrow b \rightarrow c \rightarrow d)$ и $(d \rightarrow e \rightarrow$ $\rightarrow f \rightarrow g)$ соответственно в отсутствие ТГ будут проходить точно так же, как и на термограмме рис. 1, $a$. Если направление изменения энергии Гиббса в одну сторону $(a \rightarrow b \rightarrow c \rightarrow d)$ не совпадает с направлением в обратную сторону $(d \rightarrow c \rightarrow h \rightarrow k \rightarrow g)$ в соответствии с рис. 2, $a$, то образуется петля $b h k b$ термического гистерезиса ТГ-І на рис. 4. Получается, что при наличии движущей силы кристаллизации $\Delta G_{L S}$ и переохлаждения $\Delta T_{L S}^{-}$, процессы затвердевания при $T_{S}$, и плавления при $T_{L}$ происходят изотермически, т. е. равновесно.

Для анализа поведения энергий Гиббса в случае ТГ-ІІ проанализируем функции $G_{L}(T)$ и $G_{S}(T)$. С учетом процесса зародышеобразования кривая $G_{L}(T)$ ниже температуры плавления $T_{L}$ должна сближаться к кривой $G_{S}(T)$ по пути $b \rightarrow e_{k}$. При равновесной кристаллизации путь изменения энергий Гиббса $d \rightarrow c \rightarrow b \rightarrow g$ совпадает c направлением в обратную сторону при нагревании $a \rightarrow b \rightarrow c \rightarrow d$, как и на термограммах рис. 1 и 2 . После охлаждения расплава неравновесной кристаллизации от температуры $T_{\min }$ и охлаждения твердой фазы до точки $e_{k}$ энергия $G(T)$ должна меняться в направлении $d \rightarrow e_{k} \rightarrow e \rightarrow b \rightarrow g$, а при нагревании (с учетом плавления) по пути $a \rightarrow b \rightarrow c \rightarrow d$. Вместе эти кривые образуют своеобразную гистерезисную фигуру. Для изображения путей изменения функции $G(T)$ после начала кристаллизации возможны варианты. Либо она должна меняться по направлению $M \rightarrow N$, тогда завершение процесса затвердевания должно происходить при температуре $T_{\min } \mathrm{c}$ дальнейшим подъемом температуры от $T_{\min }$ до $T_{L}$, чего в принципе быть не может, либо по направлению $M \rightarrow b(c)$. Однако в данном случае не учитываются процессы зародышеобразования, а структура жидкости остается идеальной, как и при темпера- туре выше температуры плавления. С учетом процесса зародышеобразования кривая $G_{L}(T)$ ниже температуры плавления $T_{L}$ должна сближаться к кривой $G_{S}(T)$ по пути $b \rightarrow e_{k}$. Следует учитывать еще одно немаловажное обстоятельство: весь процесс затвердевания состоит из трех составных частей - зародышеобразования за инкубационный период $\tau_{1}$, коагуляции зародышей за время $\tau_{2}$ и дальнейшей изотермической кристаллизации за время $\tau_{3}$. Коагуляции зародышей начинаются только в случае достижения критической границы метастабильного состояния, т. е. температуры $T_{\min }$ в одной точке $e_{k}$ с последующим быстрым подъемом температуры до $T_{L}$ (по прямой $e_{k} \rightarrow e$ ). Эти этапы и особенности должны также быть отражены на графиках $G_{L}(T)$ и $G_{S}(T)$. Поэтому остается один вариант, показанный на рис. 4. На этом рисунке отражены и три составные части изменения энергии Гиббса при затвердевании: $\Delta G_{1}$ на этапе зародышеобразования, $\Delta G_{2}$ на этапе коагуляции зародышей, $\Delta G_{3}$ на этапе докристаллизации.

В данном случае проявляется своеобразная петля (см. замкнутую заштрихованную область, ограниченную пунктиром), свидетельствующая о гистерезисном характере изменения энергий Гиббса, так как при нагревании они меняются по направлению $a \rightarrow b(c) \rightarrow d$, а при охлаждении по направлению $d \rightarrow e_{k} \rightarrow e(f) \rightarrow a(g)$.

Имеется „весомый“ аргумент трактовки термических гистерезисных явлений, основанный на том факте, что твердые тела при плавлении практически не перегреваются, а жидкости кристаллизуются после достижения определенных переохлаждений. В работе [11] было показано, что при образовании зародышей жидкой фазы при плавлении и зародышей кристаллов при кристаллизации имеет место гистерезисный эффект, связанный с дефектами кристалла в виде дислокаций. Наличие дефектов в кристалле „облегчает“ их плавление, а для образования кристалла с дефектами и их удержания в зародыше требуется дополнительная энергия, что затрудняет и задерживает процесс формирования реальных кристаллов. Возможно, гистерезисные эффекты при плавлении и кристаллизации как раз и связаны с реальной структурой конденсированных сред.

\section{Список литературы}

[1] Соколов Д.Н., Сдобников Н.Ю., Комаров П.В., Самсонов В.М. // Строение и свойства металлов и шлаковых расплавов: в 4 т: Труды XIII Рос. конф. Екатеринбург. 2011. РАН. Секция физ.-хим. основ металлург. процессов. 2011. C. 26-29.

[2] Климов В.А., Тимофеева И.О., Ханин С.Д., Шадрин Е.Б. и др. // ЖТФ. 2002. Т. 72. Вып. 9. С. 67-74.

[3] Замулин И.С., Гафнер С.Л. // Матер. Междунар. научнотехн. конф. М. Intermatic, 2012. Ч. 1. С. 15-18.

[4] Борыняк Л.А., Чернышов А.П. // Научный вестник Новосибирского гос. техн. ун-та. 2014. № 1 (54). С. 172-179.

[5] Берг Л.Г. Введение в термографию. М.: Наука, 1969. 480 с. 
[6] Уэнландт У. Термические методы анализа. М.: Мир, 1978. $527 \mathrm{c}$.

[7] Шестак Я. Теория термического анализа. М.: Мир, 1987. $456 \mathrm{c}$.

[8] Александров В.Д. Кинетика зародышеобразования и массовой кристаллизации переохлажденных расплавов и аморфных сред. Донецк: Донбасс, 2011. 591 с.

[9] Александров В.Д., Покинтелица Е.А. Кластерно-коагуляционная кристаллизация переохлажденных жидкостей. Теория кристаллизации расплавов. Palmarium Academic Publishing, 2015. $176 \mathrm{c}$.

[10] Кидяров Б.И. Кинетика образования кристаллов из жидкой фазы. Новосибирск: Наука, 1979. 79 с.

[11] Александров В.Д., Соболь О.В. // ЖФХ, 2007. Т. 81. № 11. C. 2100-2103. 